\title{
POLITECNIA DA APRENDIZAGEM E A CENTRALIDADE DO TRABALHO EM PROUDHON: ALGUNS BREVES APONTAMENTOS
}

\author{
Leonardo Leonidas Brito \\ E-mail: leobritouerj@hotmail.com \\ Colégio Pedro II \\ DOI: 10.15628/rbept.2020.11235
}

Artigo submetido em: set/2020 e aceito em: dez/2020

\begin{abstract}
RESUMO
O artigo em tela apresenta-se como uma possibilidade, no campo de estudos na pós graduação em Educação profissional e tecnológica (EPT), de diálogo e reflexão estritamente teórica acerca da questão da politecnia da aprendizagem e da centralidade do trabalho a partir da tradição inaugurada pelos socialistas libertários em meados do século XIX. Especificamente, tomando como referência os escritos do filósofo social francês Pierre Joseph Proudhon, que inaugurou, a partir de 1840, o que se convencionou chamar de anarquismo. Corrente do movimento socialista dos trabalhadores europeus no século XIX marcada por original, radical e consistente crítica às formas de dominação erigidas pelo modelo capitalista industrial advindo das transformações disruptivas históricas ocorridas no século XVIII.
\end{abstract}

Palavras-chave: Anarquismo, politecnia da aprendizagem, Proudhon.

\section{POLYTECHNIC OF LEARNING AND THE CENTRALITY OF WORK IN PROUDHON: SOME BRIEF NOTES.}

\begin{abstract}
The article presents itself as a first possibility, in the field of studies of professional and technological education, for dialogue and strictly theoretical reflection on the issue of the polytechnic of learning and the centrality of work based on the tradition inaugurated by the socialists libertarians in the mid-19th century. Specifically, taking as a reference the writings of the French social philosopher Pierre Joseph Proudhon, who inaugurated, from 1840, what was conventionally called anarchism. Current of the socialist movement of European workers in the 19th century marked by original, radical and consistent criticism to the forms of domination erected by the industrial capitalist model arising from the historical disruptive transformations that occurred in the 18th century.
\end{abstract}

Keywords: Anarchism, polytechnic learning, Proudhon. 


\section{INTRODUÇÃo}

O artigo em tela apresenta-se como uma possibilidade de diálogo e reflexão teórica acerca da questão da politecnia da aprendizagem e da centralidade do trabalho a partir da tradição inaugurada pelos socialistas libertários em meados do século XIX. Especificamente, tomando como referência os escritos do filósofo social francês Pierre Joseph Proudhon, que inaugurou, a partir de 1840, o que se convencionou chamar de anarquismo. Corrente do movimento socialista dos trabalhadores europeus no século XIX marcada por original, radical e consistente crítica às formas de dominação erigidas pelo modelo capitalista industrial advindo das transformações disruptivas históricas ocorridas no século XVIII.

O texto parte de uma premissa fundamental: ambas as questões colocadas aqui - a politecnia da aprendizagem e a centralidade do trabalho-, estruturantes teóricas da Educação Profissional e Tecnológica, em geral, e para o Mestrado Profissional em Educação Profissional e Tecnológica (ProfEPT), em particular, são, no campo das ideias socialistas, originalmente colocadas por Proudhon e não por Karl Marx como aponta, em grande medida os principais intelectuais formuladores deste campo no Brasil (Frigotto, Ciavatta e Ramos). Ė interessante notar que no verbete "Educação Politécnica" produzido pela Escola de Saúde Joaquim Venâncio, da Fiocruz, o Rodrigues é peremptório ao afirmar que "é consenso, entre os pesquisadores da área de trabalho e educação, que o conceito de 'educação politécnica' foi esboçado inicialmente por Karl Marx, em meados do século XIX."1 Em que pese a imensa contribuição do filósofo alemão para a crítica à Economia Política liberal, smithiana e fundadora da "quintessência" do capitalismo em suas múltiplas dimensões materiais, é Proudhon que apresenta as críticas pioneiras, e que posteriormente, pavimentariam o caminho para o soerguimento de todo o rico e consistente debate no campo socialista (no decorrer do desenvolvimento do movimento operário), sistematizado na segunda metade do século XIX, principalmente a partir do surgimento da Associação Internacional dos Trabalhadores (AIT), em 1864, na cidade de Londres.

Como método para exposição das ideias do filósofo ácrata francês, lançaremos mão, além dos próprios escritos do autor, a interlocução com alguns comentaristas da vasta obra de P. J. Proudhon. Dos textos já traduzidos para o português agradecemos especialmente ao editor brasileiro Plínio Augusto Coelho que, há mais de três décadas se dedica à tradução e organização de variados escritos do socialista francês. Vale destacar também

\footnotetext{
${ }^{1}$ RODRIGUES, José. Verbete "Educação Politécnica". In Dicionário da Educação Profissional em Saúde. FIOCRUZ.

Disponível em http://www.sites.epsjv.fiocruz.br/dicionario/verbetes/edupol.html. Acesso 27/09/2020. São afirmações categóricas como essa e que obliteram a primazia da das formulações de Pierre Joseph Proudhon sobre o tema, desde 1840, que nos conduzem a elaboração do presente artigo.
} 
que não temos a pretensão de esgotar o debate, tendo em vista a complexidade do tema e o espaço naturalmente restrito para a publicação de um artigo acadêmico.

\section{PROUDHON: MUTUALISMO E ANTINOMIAS SOCIAIS}

Antes de abordarmos especificamente a questão da instrução politécnica para o anarquista francês, faz-se mister apontamentos acerca destas que são características fundamentais da teoria social proudhoniana. Dentro das influências teóricas estruturantes, no advento da AIT, Proudhon se situou como o expoente máximo daquilo que se convencionou chamar de socialismo libertário - em oposição ao socialismo autoritário encampado por Marx, em função da defesa deste último de um modelo de organização dos trabalhadores através da concepção clássica de partido revolucionário, em vias de construir o que se consagrou nas fileiras do marxismo de Ditadura do Proletariado. Por outro lado, para Proudhon, qualquer ideia de ditadura ou centralização de poder por parte de um grupo, ainda que em nome dos trabalhadores, seria algo absolutamente condenável, tendo em vista que a liberdade para o pensador francês é a condição última, plena e fundamental para o desenvolvimento humano. Não a liberdade tal qual proposta por pensadores como Jean Jacques Rousseau e consagrada posteriormente pelo individualismo burguês, mas aquela realizada apenas na construção coletiva. Desta forma, a anarquia surge como uma forma de construção social humana necessária a fim de buscar a garantia de todas estas liberdades individuais:

A anarquia, se posso exprimir deste modo, uma forma de governo ou constituição, na qual a consciência pública ou privada, formada pelo desenvolvimento da ciência e do direito, é por si só suficiente para a manutenção da ordem e para a garantia de todas as liberdades. ${ }^{2}$

Da mesma forma, a construção teórica de Proudhon está assentada na ideia de que se faz necessário, por todos os meios se evitar, a concentração de poder e, portanto:

(...)que a sociedade possa encontrar vantagem exclusivamente pela sua divisão em unidades de dimensões pequenas, autônomas entre $\mathrm{si}$, e federadas, ligadas pela vontade livre e sustentadas pelas livres trocas mutualistas. Neste momento a organização da educação também deveria ter seguido essa imposição, tanto que ele -

\footnotetext{
2 P. J. Proudhon, "Lettre à l'editeur du Dictionnaire Larousse" (1884) - "Carta ao editor do dicionário Larrouse" citado por CODELLO, F. A Boa Educação: Experiências libertárias, teorias anarquistas na Europa, de Goldwin a Neill. Volume 1: A Teoria. São Paulo. Editora Imaginário/Ícone editora. 2007. P. 93.
} 
Proudhon- prefigura um sistema educativo absolutamente descentrado e que corresponde a uma gestão direta da comunidade que se arroga completamente esta tarefa." (CODELLO. 2007:9495. Grifos meus).

Quanto ao método filosófico, a diferença fundamental apresentada por Proudhon em relação a pensadores herdeiros da tradição hegeliana como Marx, se apresenta na recusa do socialista francês no que diz respeito à noção de síntese. O pensamento do ácrata francês é atravessado pelo conceito de antinomia que poderia ser assim descrito: "La antinomia sería entonces la categoría primaria, bajo la forma de un equilibrio inestable y móvil. En Proudhon el principio de antinomia reemplaza al principio de superación, de inspiración hegeliana: superación de las contradicciones en una entidad englobante o 'síntesis'."3 (CORCUFF. 2016:7)

Perscrutando os escritos do socialista libertário em tela, apreende-se literalmente, da obra Da Justiça na Revolução e na Igreja: "La fórmula hegeliana [tesis-antítesis-síntesis] no constituye una tríada más que por capricho o error del maestro, quien distingue tres términos allí donde sólo existen dos, y no ha visto que la antinomia no se resuelve, sino indica una oscilación o antagonismo susceptible sólo de equilibrio." ${ }^{4}$ A dialética proudhoniana, a partir do método de pares antinômicos, buscaria abranger a pluralidade e diversidade dos fenômenos sociais. Em outras palavras, o mundo apareceria para o observador como uma "pluralidade de elementos irredutíveis e, ao mesmo tempo, antagônicos e solidários" (MOREL. 2003:21):

A antinomia é o constituinte típico deste pluralismo, é um par de forças ao mesmo tempo antagônicas e complementares. A resolução da antinomia é impossível, porque é da sua existência que resultam o movimento e a vida. A síntese é artificial ou implica a morte. No melhor dos casos estas antinomias se contrabalançam e podem alcançar um equilíbrio, sempre instável porque a perfeição não existe e somente pode ser admitida, metodologicamente, como ponto de

\footnotetext{
3 Numa tradução aproximada: "A antinomia seria então a categoria principal, na forma de um equilíbrio instável e móvel. Em Proudhon, o princípio da antinomia substitui o princípio da superação, da inspiração hegeliana: superar as contradições em uma entidade abrangente ou 'síntese"'.
}

4 "A fórmula hegeliana [tese-antítese-síntese] não constitui uma tríade mais do que por capricho ou erro do professor, que distingue três termos em que existem apenas dois e você se viu que a antinomia não foi resolvida, mas indica uma oscilação ou antagonismo suscetível somente ao equilíbrio." P. J. Proudhon citado por CORCUFF, Philippe. Antinomias y analogías como instrumentos transversales en sociología: A partir de Proudhon y de Passeron. Cultura representaciones soc [online]. 2016, vol.10, n.20, pp.42-58. ISSN 20078110. P. 7. (Ver bibliografia). 
partida de um raciocínio e jamais como resultado, como possibilidade real." 5

A educação para Proudhon possui necessariamente uma dimensão libertadora e de repulsa a toda e qualquer forma de autoridade: "Quanto mais o Homem é ignorante, maior é a sua obediência, e mais absoluta é a falta em seu direcionamento". ${ }^{6}$ Para tal é necessário libertá-lo de todo condicionamento que não derive estritamente da necessidade. Igualmente, para o anarquista francês, o valor ontológico e educativo do trabalho é inerente à realização que este permite ao indivíduo, quando este mesmo indivíduo dispõe plenamente do que resulta da sua atividade laboral. $O$ trabalho é inevitavelmente o centro econômico da vida humana.

\section{PROUDHON E A INSTRUÇÃO POLITÉCNICA}

Teçamos algumas breves considerações sobre a percepção acerca da centralidade do trabalho já exposta pelo "filósofo da miséria". Observações que são importantes para que tenhamos clareza da defesa intransigente que Proudhon fez da politecnia da aprendizagem como meio para libertação do homem de sua condição de subalternidade.

Poderíamos tratar de um "alfabeto do trabalhador"7, segundo o ácrata francês, que à título de alegoria, mostraria o papel axial que o trabalho exerce na condição humana. "Trabalho" e "movimento" como acepções inerentes a um mesmo processo do ato de "modelar" a vida social:

\begin{abstract}
"O homem nada cria, dizem com razão os economistas; ele modela. - o que é modelar? Perguntais. Resposta: é mover. - Retomo: só o movimento, imprimindo à matéria, não lhe dá a forma deseja, não constitui o trabalho, é preciso que esse movimento esteja em relação com o objetivo a alcançar, em equação com a sua ideia, em medida, em equilíbrio. É o que nos mostra à primeira vista o alfabeto do trabalhador". 8
\end{abstract}

\footnotetext{
${ }^{5}$ José Carlos Orsi Morel na apresentação de PROUDHON, P. J. Sistema das Contradições Econômicas ou Filosofia da Miséria. (ver bibliografia)

${ }^{6}$ PROUDHON. O que é Propriedade? 1841. Citado por CODELLO. 2007 P. 95

7 Alfabeto do trabalhador, segundo Pierre Joseph Proudhon, alegoria para compreensão da centralidade do trabalho na vida social e a não especialização do trabalhador. "'A" (Barra ou Alavanca); "B" (Gancho, Barra Recurva); "C" (Pinça); "D" (Liame); "E" (Martelo); F (Ponta lança, pique, dardo, flecha, aguilhão, agulha, etc.); "G" (Cunha); "H" (machado); "I" (lâmina); "J" (serra); "K" (Pá); "L" (Picão/ picareta); "M" Forquilha); "N" (rampa ou plano inclinado); "O" (rolo, dando por sua seção, a roda, que é também a polia); "P" (Cano); "Q" (Ramo e Leme); "R" (Arco ou mola); "S" (Régua); "T" (nível); "U" (esquadro); "V" (compasso); "X" (pêndulo ou prumo); "Y" (balança); "Z" (Círculo)." PROUDHON. 2019. P. 116.
}

8 PROUDHON. 2019 P. 116. (ver bibliografia) 
Trabalho e divisão (compreendida como especialização do trabalhador, tal qual defendida pela economia política liberal - Smith, Ricardo e Jean Baptiste Say) são percebidos por Proudhon como antinomias. O efeito deste "trabalho parcelar" seria 0 de subjugar o homem, condenando-o ao embrutecimento. Neste sentido, "o trabalho que deveria trazer a consciência a seu clímax e torná-la cada vez mais digna de felicidade, conduzindo pela divisão parcelar ao desmoronamento do espírito, diminui o homem da parte mais nobre de si, minorat capitis ${ }^{9}$, e o rejeita na animalidade..."10

A indissociabilidade entre "a força que dirige a mão do operário" e o "cérebro do filósofo" (PROUDHON. 2019:117) é condição basilar para a proposição do que o anarquista de Besançon chamou de "Enciclopédia ou politecnia da aprendizagem". Segundo ele, "a primeira parte da proposição está, portanto, estabelecida: a ideia, com suas categorias, nasce da ação; em outros termos, a indústria é mãe da filosofia e das ciências". (PROUDHON, 2019: 123 - grifo do autor-).

Demonstrada esta relação, há de discorrer sobre a segunda propositura: a ideia se tornar ação. O que para Proudhon restava dizer que "a filosofia e as ciências devem ingressar na indústria, sob pena de degradação para a humanidade...." (PROUDHON, 2019:123).

Na percepção proudhoniana acerca do trabalho e a indivisibilidade entre a dimensão manual e intelectual deste, mais uma vez, aparece a dialética serial característica de sua "filosofia da miséria". Fica evidente para o anarquista francês o fato de que:

"O trabalho apresenta dois aspectos contrários, um subjetivo, o outro objetivo, fatal. Sob o primeiro aspecto, ele é espontâneo e livre em princípio de felicidade: é a atividade em exercício legítimo, indispensável à saúde da alma e do corpo. Sob o segundo aspecto, o trabalho é repugnante e penoso, princípio de servidão e embrutecimento".

Esses dois aspectos do trabalho são inerentes um ao outro, como alma e corpo: daí resulta, a priori, que toda fadiga e repugnância, no trabalho, não poderia desaparecer completamente." 11

È notório nos escritos do "pai do anarquismo" o papel deletério da hiperespecialização do trabalho para o operário. "Quanto mais o trabalho divide-se $e$ as máquinas aperfeiçoam-se, menos o operário vale; consequentemente, menos ele é pago; portanto, por um mesmo salário, mais

\footnotetext{
9 "Cabeça diminuída".

10 PROUDHON. 2003. P. 183 (Ver bibliografia)

11 PROUDHON. 2019. PP 123-124.
} 
sua tarefa aumenta", reafirmava Proudhon em 1858. Grifa-se a expressão em itálico, tem em vista que a formulação original do autor acerca dos problemas relacionados à extrema divisão do trabalho, como já apontamos, remete ao Sistema de Contradições Econômicas de 1846. Aliás, vale ressaltar que este debate é retomado por Marx em sua célebre resposta à Filosofia da Miséria do Sr. Proudhon, publicada no ano subsequente:

\begin{abstract}
A divisão do trabalho reduz o operário a uma função degradante; a esta função degradante corresponde uma alma depravada; à depravação da alma convém uma redução sempre crescente do salário. E para provar que esta redução dos salários convém a uma alma depravada, o sr. Proudhon diz, por desencargo de consciência, que é a consciência universal que assim o quer. A alma do sr. Proudhon estará incluída na consciência universal?

As máquinas são, para o sr. Proudhon, "a antítese lógica da divisão do trabalho", e, com o apoio da dialética, ele começa por transformar as máquinas em oficina. ${ }^{12}$
\end{abstract}

Por outro lado, de acordo com a perspectiva proudhoniana, seria esta ultra especialização e "a monotonia do labor" as responsáveis pela aquisição da consciência pelo próprio trabalhador de sua degradação. Ser reduzido à condição de mera engrenagem da produção em geral, o levaria ao desespero: “(...) por falta de uma ciência positiva, perde o equilíbrio; o coração depravase, e o homem acaba nos sonhos da utopia, nas loucuras do iluminismo e nas raivas da impotência". (PROUDHON. 2019: 128). A lógica do capital, ao querer "mecanizar o operário", teria, ao fim e ao cabo, feito pior: "tornaram-no inábil e mau" (PROUDHON. 2019: 128). Nota-se mais uma vez a dialética serial atravessando a análise do socialista libertário. É tácito concluir o paradoxo se considerarmos a realidade da lógica do capital- observado por Proudhon que aponta que o desenvolvimento pleno da indústria, e por sua vez da própria ciência, só poderá ocorrer se o ensino a ser dado àquele que detém o controle sobre o trabalho "abranja todo o seu círculo" (PROUDHON. 2019:128); a possibilidade de escolha do método e da especialidade "chegue ao operário, bem como ao politécnico, após a conclusão do curso completo de estudos?"

\footnotetext{
Mas está claro que a indústria, não mais do que as ciências, não pode ser parcelada sem parecer: o homem cujo gênio circunscrito em uma profissão nada sabe das outras é como aquele, tendo aprendido a assinar seu nome pelas iniciais, nada sabe do resto do alfabeto.
}

\footnotetext{
12 MARX, K. Miséria da Filosofia: resposta à filosofia da miséria do Sr. Proudhon. Cap. II "A metafísica da Economia Política", parágrafo II - A divisão do trabalho e as máquinas. Disponível em https://www.marxists.org/portugues/marx/1847/miseria/cap05.htm. Acesso dia 23/09/20.
} 
Todo conjunto ou nada: é a lei do trabalho bem como do saber. A indústria é a forma concreta dessa filosofia positiva que se trata hoje de verter nas almas no lugar das crenças extintas, filosofia que profetizou e invocou, há um século, o mais vasto gênio dos tempos modernos, o pai e o hierofante da Enciclopédia, DIDEROT. ${ }^{13}$

Infere-se também da teorização proudhoniana a conclusão acerca da impossibilidade da realização plena da educação politécnica na sociedade capitalista. A relação entre revolução e educação é indissociável, tendo em vista que para a superação da "educação servil" (DOMMANGET. 1974: 278) seria necessária a ruptura radical, uma vez que:

\begin{abstract}
No estado atual de nossa sociedade, a instrução da juventude, com exceção de uma elite de privilegiados, é um sonho de filantropia; que, do mesmo modo que o pauperismo, a ignorância é inerente à condição do trabalhador; que esta inferioridade intelectual das classes laboriosas é invencível, ainda mais num regime político hierarquizado, com um feudalismo capitalista e industrial, um mercantilismo anárquico, esta instrução, desejável em si, seria desperdiçada, mesmo perigosa; e que não é sem razão que os homens de Estado, ao mesmo tempo que se ocupam da instrução do povo, a reduzem sempre aos simples elementos. ${ }^{14}$
\end{abstract}

O princípio fundante da pedagogia socialista, para o "filósofo do trabalho" é "a igualdade de cultura pelo ensino profissional, coisa que se exprime pela expressão 'politecnia da aprendizagem', sistema que se traduz hoje pela 'escola oficina' (DOMMANGET. 1974 :280). ${ }^{15}$

Das consequências da aprendizagem politécnica é possível perceber "que a condição do trabalhador muda completamente; que o tormento e a repugnância inerentes ao labor no estado atual apagam-se gradualmente ante a deleitação que resulta para o espírito e o coração do próprio trabalho" (PROUDHON. 2019:132). Trabalho e liberdade serão categorias que convergirão, apenas, nesta nova realidade marcada pelo controle por parte daquele que realiza o labor. E o que Proudhon classificaria como o "homem que passa a existir por si mesmo" (PROUDHON. 2019:136), porque:

A ideia de fazer o trabalhador gozar, em plena civilização, da independência edênica e dos benefícios do trabalho, por uma educação simultânea da inteligência e dos órgãos, que, dotando-o da totalidade da indústria adquirida, assegurar-lhe-ia por isso mesmo

\footnotetext{
13 PROUDHON. 219. P. 129.

14 PRODHON apud DOMMANGET. Maurice. 1974. P. 278.

${ }^{15}$ A expressão 'escola oficina' aparece nas traduções portuguesas e brasileiras das obras de Proudhon. A exata expressão em francês é "école-atelier".
} 
a plenitude de sua liberdade, essa ideia é seguramente irrepreensível como concepção, e de imenso alcance. ${ }^{16}$

Os resultados desta pedagogia politécnica apagariam todos os vestígios do que o pensador anarquista chamaria de "vampirismo transcendental". Noutras palavras, a exploração pelo homem. Responsável pela animalização daqueles subordinados ao "trabalho parcelar". De fato, para a percepção libertária de socialismo de Pierre Joseph Proudhon, a politecnia da aprendizagem é o exato oposto do trabalho parcelar:

(...) Dotar os operários de uma capacidade profissional completa é, com efeito, libertá-lo da tutela dos agentes de domínio, é sapar a aristocracia do talento, que se origina, segundo Proudhon, 'não numa superioridade real, mas na mutilação de pessoas'. Porque sem negar que a 'inteligência difere e há de diferir sempre de um indivíduo para o outro', Proudhon pensa igualmente que ela representa 'na origem, uma força igual em todos', que, pelo seu desenvolvimento, garante $o$ progresso social e a igualdade $(\ldots)^{17}$

Se para a filosofia do trabalho proudhoniana a organização do ensino é, ao mesmo tempo, a "condição da igualdade e a confirmação do Progresso" (DOMMANGET. 1974: 279), a transformação social era, da mesma forma um imperativo. Não apenas - e condizente à análise social da filosofia do trabalho do anarquismo de Proudhon que prima pelo aspecto material/econômico - a dimensão estritamente política da ação da classe trabalhadora (a revolução) seria suficiente para a transformação disruptiva almejada pelo socialismo libertário. Uma educação plena, politécnica e emancipadora do Homem está necessariamente circunscrita num outro modelo de organização social:

(...)Proudhon pensa que a instrução popular [é de uma absoluta e radical impossibilidade na ordem capitalista]. Principalmente, ele não vê remédio fora de uma 'sociedade justiceira, mutualista e livre', o que ele chama algures 'a federação universal', e que correspondia, como sabemos, ao seu ideal socialista (...). É preciso dispensar uma educação 'seriamente liberal, à altura do sufrágio universal, e que concorra, com as instituições de mutualidade e de segurança, com a associação operária e a federação das comunas e das províncias, para estabelecer um certo nível entre as corporações, os recursos e os meios de fortuna. ${ }^{18}$

\footnotetext{
16 DOMMANGET. 1974. P 278.

17 DOMMANGET. 1974. P. 283

18 DOMMANGET. 1974.PP. 279-280
} 


\section{CONSIDERAÇÕES FINAIS}

Este artigo se circunscreve como uma tentativa inicial de diálogo, no âmbito de estudos da Educação Profissional e Tecnológica em geral, e no mestrado profissional em EPT (ProfEPT) em particular, com a perspectiva pedagógica crítica que aponta o marxismo como o ponto de partida das reflexões acerca da educação politécnica e da centralidade do trabalho como categoria ontológica da condição do Homem. Nossa premissa é clara: a originalidade destas formulações está, no tocante à tradição socialista do século XIX, nas contribuições do pensador anarquista Pierre Joseph Proudhon.

Desta forma, procuramos trazer para o debate, aspectos primaciais das teorizações proudhonianas e que podem contribuir para elucidar omissões (deliberadas ou não) acerca das categorias de análise apontadas acima por nós. Tem-se o fito também de agregar ao debate acerca das bases conceituais em EPT, o pensamento proudhoniano, já exposto com rigor em estudos sobre a História da educação das classes trabalhadoras, no Brasil e na França ${ }^{19}$, e de forma igualmente inovadora no campo da História ${ }^{20}$.

Acreditamos que inserir ao debate na EPT categorias de análise proudhonianas, como a dialética serial, e apontar a primazia dos escritos do ácrata francês acerca da politecnia da aprendizagem pode contribuir sobremaneira para ampliar as bases teóricas das pesquisas em nosso campo de estudo. Desconstruir equívocos que - quando ocorrem por desconhecimento ou inapetência- cabe ao educador libertário o zelo para tornar didática a "novidade". No entanto, quando nos deparamos com a falsificação histórica", o "bom combate" faz-se necessário. Ademais, justo. Tendo em vista que cabe ao estudioso do passado a devida objetivação daquilo que cabe ao seu recorte histórico. Como certa vez afirmou o literato e historiador Prosper-Olivier Lissagaray, à propósito da Comuna de Paris de 1871 (experiência a qual fora testemunha ocular), "aquele que conta ao povo lendas revolucionárias, aquele que diverte-se com contos sensacionalistas, é tão criminoso quanto o geógrafo que desenha cartas falsas para os navegadores". ${ }^{21}$

19 Destaco a relevância de pesquisas, no campo da Educação lato sensu, de filósofo e pedagogo Silvio Gallo, autor de Pedagogia Libertária - Anarquistas, Anarquismos e Educação. São Paulo: Editora Imaginário/ Editora da Universidade Federal do Amazonas, 2007 e do pioneiro Pedagogia do Risco Experiências Anarquistas em Educação, 1995. Do historiador Rogério de Castro, autor da original tese de doutorado Nem Prêmio, nem castigo! A escola Moderna como ação revolucionária dos sindicatos operários durante a Primeira República (São Paulo, 1909-1919), também já publicada. E das reflexões do professor e pesquisador emérito em Ciências da Educação da Universidade de Paris-Nanterre, Hugues Lenoir, "A Comuna de Paris e a Educação" e "Educação libertária, Educação crítica?", dispostas para o português pelo Instituto de Estudos Libertários (IEL) em 2018 -ver bibliografia-

20 Grifo em especial a publicação Negras Tormentas: o federalismo e o internacionalismo na comuna de Paris do historiador Alexandre Samis. Este título, inclusive, já pé considerado em círculos anarquistas europeus como a mais completa publicação não europeia acerca do federalismo proudhoniano e da comuna de Paris.

${ }^{21}$ Prosper-Olivier Lissagaray. História da Comuna de Paris de 1871. 
Com o mesmo ânimo narrativo e analítico de Lissagaray pretendemos trazer para as bases conceituais e teóricas da Educação Profissional e Tecnológica a perspectiva proudhoniana e sua contribuição para uma pedagogia crítica e emancipatória das classes subalternizadas.

\section{REFERÊNCIAS}

CASTRO, Rogério. Nem Prêmio, nem castigo! A escola Moderna como ação revolucionária dos sindicatos operários durante a Primeira República (São Paulo, 1909-1919). Uerj. Faculdade de Educação. Tese de doutorado. 2014.

CODELLO, Francesco. A Boa Educação: Experiências libertárias, teorias anarquistas na Europa, de Goldwin a Neill. Volume 1: A Teoria. São Paulo. Editora Imaginário/Ícone editora. 2007.

CORCUFF, Philippe. Antinomias y analogías como instrumentos transversales en sociología: A partir de Proudhon y de Passeron. Cultura representaciones soc [online]. 2016, vol.10, n.20, pp.42-58. ISSN 2007-8110. P. 7. Acessado em 01/08/20.

DOMMANGET, Maurice. Os Grandes Socialistas e a Educação. Braga. Biblioteca Universitária. 1974.

FRIGOTTO, Gaudêncio; CIAVATTA, Maria; RAMOS, Marise (orgs.). Ensino médio integrado: concepção e contradições. São Paulo: Cortez, 2005. GALLO, Silvio. Pedagogia Libertária - Anarquistas, Anarquismos e Educação. São Paulo: Editora Imaginário/ Editora da Universidade Federal do Amazonas, 2007.

GALLO, Silvio. Pedagogia do Risco Experiências Anarquistas em Educação.São Paulo. Papirus. 1995.

MARX, Karl. Miséria da Filosofia: resposta à filosofia da miséria do Sr. Proudhon. Cap. II "A metafísica da Economia Política", parágrafo II - A divisão do trabalho e as máquinas. S.d.

LENOIR, Hugues. A comuna de Paris e a Educação; James Guillaume, pioneiro de uma pedagogia emancipadora; Educação libertária, Educação crítica? São Paulo. Intermezzo Editorial. 2018.

LISSAGARAY, Prosper-Olivier. História da Comuna de Paris de 1871(Versão portuguesa A Comuna de Paris). Pdf. Disponível em https://teoriadoespacourbano.files.wordpress.com/2013/04/lissagaray-acomuna-de-pais-1877.pdf.

Disponível em https://teoriadoespacourbano.files.wordpress.com/2013/04/lissagaray-acomuna-de-pais-1877.pdf. Acesso em 27/09/2020. 
PROUDHON, P. J . O que é Propriedade? Lisboa. Editorial Estampa. 1975. .Sistema das Contradições Econômicas ou Filosofia da Miséria. São Paulo. Ícone. 2003.

Da Justiça na Revolução e na Igreja: Filosofia, Justiça e ‘Politecnia da Aprendizagem'. São Paulo, Intermezzo Editorial. 2019.

Da Capacidade Política da Classe Operária. São Paulo. Intermezzo Editorial. 2019.

SAMIS, Alexandre. Negras Tormentas: o Federalismo e o

Internacionalismo na Comuna de Paris. São Paulo. Hedra. 2011. 